\title{
RURAL SOCIAL ORGANISATION
}

\author{
by \\ E. W. HOFSTEE \\ Agricultural University \\ Wageningen, Netherlands
}

Sociology is the science of everyday human life; that is its pride, but also its curse. The concepts sociology uses are for thef reater part derived from colloquial language, which means from words and terms which as a rule are used in a rather vague and inexact way. To make them suitable for scientific use, they have to be purified and their meaning has to be restricted to one, well-defined catogory of phenomena. That usually means that the sociologist has to make a choice. Since in ordinary language words are used in a vague way they can often indicate different, but more or less related phenomena. Thus a sociologist who wants to express a certain well defined concept by using a certain word is using perhaps only part of the possible meanings of this word. Another sociologist who uses the same word but for a concept with a different meaning from that his colleague wanted to express, is able to do so without coming into conflict with the every-day use of the word.

Sociology, therefore, suffers from a great confusion in its terminology. Sociological dictionaries have been of little help to resolve it.

The term social organisation is no exception. Its components, the words social and organisation are used and perhaps misused to cover a broad diversity of meanings which often have little relation to one another. Hence, although the combination social organisation as such does not belong to the vocabulary of the man in the street, it gives sociologists the freedom to use the term for many different concepts. And they have used this freedom with eagerness! Znaniecki states that a malicious critic of sociology could hardly find a better way of arousing scepticism about its scientific value than by collecting the definitions given by sociologists of social organisation (Znaniecki, 1945).

In one respect almost all sociologists who have grappled with the problem of social organisation agree, that ithas to do with the division of functions in a social entity. Many of them add, that co-operation is a fundamental and even an essential element of organisation (van Doorn, r 956, p. 33). This is more or less selfevident as division of functions without co-operation between those who perform these different functions means disorganisation. Except for this starting point the 
theories of the students of social organisation have little in common. An important difference of opinion exists as to the question whether organisation should be used in the sense of an activity or a process which leads to functional differentiation, or a in more passive sense, namely of a condition or a phenomenon resulting from an activity or a process.

When organisation is to mean an activity, there still may be a difference of opinion whether it should mean purposeful activity and nothing else, or, as many sociologists maintain, it should include also less conscious and even unconscious behaviour.

In the first case, organisation is considered as planned action executed by an organiser or an organising body, and meant to serve certain concrete, well defined ends. We find this concept of organisation in particular among sociologists who are interested in the social problems of organisation in industry and related fields. An example is the Dutch sociologist van Doorn (1956, p. 289), who defines organisation as: "a social technique comprising simultaneously a functionalisation and coordination of human action in relation to objective aims". But other sociologists without special interest in industrial sociology, hold the same opinion (Johannessen, I955). It is hardly necessaty to point out that organisation defined in this way is of enormous importance in modern life. Often the term organisation is used without the adjective social but as van Doorn stresses in his definition, organisation is a social technique.

When social organisation is not defined as purposeful activity but as a process including all human behaviour leading to functional differentiation, we are dealing with a quite different concept. When the process of functional differentiation is not directed totally or primarily by the conscious will of an organiser or an organising body, this usually means that clear, well-defined goals are also lacking, even if a vague general aim may be present. If - to take a Dutchl example we speak in the Netherlands of the social organisation of the newlycolonised Zuiderzee-polders, we are concerned with a process which - notwithstanding the far seeing planning for this area - is only partly consciously directed. It will be the result of a multitude of forces and influences which no one controls completely, and in a democratic country, no one wants to control completely. 'Those who are in charge of the colonisation have perhaps a general idea of the kind of society they would like to see realised in these polders. This, however, is not a fixed goal but only a hope and one which is not even officially sanctioned. In fact, there is no official statement, not even in 
general terms, as to the kind of organisation of social life the Dutch government would like to see in this area.

The term organisation as an activity is often used in relation to the development of functional differentiation within newly settled areas, such as new towns, colonies, suburbs etc. In all these cases however, the process of functional differentiation is a result not only of purposeful planned action but also of less clearly directed and even partly unconscious behaviour.

It is probably organisation of this kind that Earp had in mind, when he defined in Fairchild's Dictionary of Sociology (I944) organisation as "a process, which differentiates one part from another in a functional sense and which at the same time creates an integrated complex of functional relationships within the whole".

When we use the term organisation in the passive sense, namely in the sense of a condition or a phenomenon which results from a certain action or process, we can again differentiate between two concepts.

On the one hand organisation is used to indicate an organised group. It is quite usual to refer to voluntary associations of all kinds as organisations. This mostly implies the existence of clear-cut rules governing the functional differentiation within the group and the activities of the members within the framework of the group as a whole.

On the other hand organisation in the passive sense is also used to indicate a condition or quality of a certain social entity. Theoretically social organisation in this sense can be used in relation to every social entity with a certain amount of functional differentiation particularly in relation to more complex social units. It is frequently used by social anthropologists to indicate, for example, the functional differentiation within certain tribal systems, but it is equally used in relation to modern western societies. We speak, for example, of the social organisation of the Norwegian society. Here social organisation does not normally imply a well-defined, strictly co-ordinated set of rules which determines the division of functions and directs the action of the total entity. The social organisation of every country shows an almost chaotic mixture of formal rules, customs, habits, personal relationships, arrangements, unconscious behaviour etc., which result in a certain functional differentiation without an over-all co-ordination which would transform the sum of the activities of the component parts into a concerted action. Sometimes a society will act consciously as a whole in a certain respect, but this action will usually be only a part of the total activity of this society.

In this case social organisation is often used in a rather loose way and 
not clearly distinguished from related concepts such as social structure or even social life in general. If social organisation as a concept is to have any value, we have to use it strictly in its essential meaning, of functional differentiation within a certain social entity.

Since the famous Hawthorne experiment it has become customary to make a difference between formal and informal organisation. By formal organisation we understand an organisation created and maintained by explicitly formulated, often written rules fixed by competent authority, for example, the management of a factory, the general meeting of a voluntary association or the parliament of a state. By informal organisation we understand a more or less spontaneously developing or developed functional differentiation depending on personal relationships between those who are concerned.

When we apply this distinction of formal and informal organisation to the four different sub-concepts of organisation mentioned earlier, it is apparent that, when we speak of social organisation as a planned action, we have todo with a phenomenon in which the formal element predominates. If by social organisation we mean an organised group, we are concerned with organisation in the formal sense if this organised group has resulted from planned organisational activity. In the case of the two other subconcepts organisation is usually a mixture offormaland informal elements.

Some authors reject the distinction between formal and informal organisation as it is usually made (van Doorn, x956). van Doorn maintains that even in the most strictly organised social group the activity of the members is never based entirely on the organisational blue print. If members were to follow the blue print strictly the organisation would not work. Every organisational function, van Doorn remarks, implies an interpretation (re-interpretation) on the part of the acting members. I think van Doorn is right, when he points out, that even in the most strictly preconceived organisation there will always develop and must develop an element which we are accustomed to call informal. van Doorn's interpretation depends on on his definition of organisation, which covers only one of the four sub-concepts mentioned.

When we accept a broader concept of social organisation, defining it as functional differentiation in general, the distinction between formal and informal organisation is very useful. In that case the study of the relative importance of formal and of informal elements in the organisation of a social entity, and their relation to function, structure and culture of this entity, becomes an essential element in the understanding of group and society. 
This leads us to out theme of rural social organisation. The choice of the term indicates already that it was meant in a rather broad sense and not to refer only to the organisation of certain limited groups, but also to rural society as a whole. Undoubtedly the organisation of associations and other special groups in the countryside will demand our attention, but I think they will always be considered in the framework of rural society as a whole.

When we think of rural society as a whole, in particular rural society in Europe today, we hardly can avoid the problem of the relative importance of formal and informal elements. One can even postulate that the problem of the relative importance of formal and informal elements in rural social organisation and changes therein is one of the main subjects in European rural sociology. It is not only a problem in the academic sense, but it plays an important part in rural and in agrarian policies. These terms may not always be used, but there is a permanent and sometimes heated discussion between those who emphasise the value of informal organisation for rural life and for society as a whole, and those who are convinced of the necessity of an adjustment of the rural population to formal organisation which becomes more and more dominant in Western society.

On the one hand, there are those who believe that the countryside has and should have a culture essentially different from urban culture, one of its aspects being a predominance of informal elements in its social organisation. On the other hand, there are those who think that there is no essential difference between the culture of the cities and that of the countryside and that, in any case in modern societies, it is impossible to maintain such a difference. In their opinion to attempt the artificial preservation of this cultural difference - for example with regard to the type of social organisation - is detrimental to the countryside.

It was Tönnies (I9I2) who in his famous book "Gemeinschaft und Gesellschaft" expressed as early as I 887 for the first t:me this problem in sociological terms. The dichotomy of Gemeinschaft and Gesellschaft is not quite identical with that of formal and informal organisation. Essentially Gemeinschaft and Gesellschaft are not types of social organisation but types of social entities (Verbände). Theoretically a Gemeinschaft can exist without any functional differentiation, but when it has an organisation it will be predominantly of an informal character. It is not quite certain whether Tönnies uses Gemeinschaft and Gesellschaft as ideal types or includes also actual social entities, for instance under Gemeinschaft, the family and the village. These actual entities will 
show some formal organisational traits but in his definition of Gemeinschaft Tönnies emphasises its informal character. Formal organisation is essential for the Gesellschaft and the contract is according to Tönnies its basis. When Tönnies speaks of Gesellscbaft in the abstract Gesellschaft is almost identical with formal organisation.

It is remarkable and does honour to Tönnies as a sociologist, that more than eighty years after he formulated his concepts, they are still very much alive in sociology, in particular in rural sociology not only in Europe but also in America. One of the best known American textbooks on rural sociology, Loomis" and Beegle's "Rural Social Systems" (1950) still uses the concepts of Gemeinschaft and Gesellscbaft as a starting point for their discussion of American rural life.

There is, however, some reason to believe that 'Tönnies' theory had a very unfortunate effect on rural sociology and the thinking about rural problems in general, especially in Europe. The theoretical basis of the two forms of social life can be criticised and is criticised in many ways (von Blankenburg, I960; Gurvitch, I950; König, I955, and Kruijt, I955), but is certainly not more shaky than that of many other wellknown and much used theoretical concepts in sociology. It is not so much the formulation of the dichotomy as such but his personal attitude to the two forms of social life which caused this bad effect.

It is surprising to discover when one reads and re-reads 'Tönnies' book how strongly the author is emotionally involved in his subject. Though he acknowledges that an increasing predominance of the Gesellschaft-type of social life in our society is unavoidable, all his sympathy lies with the Gemeinschaft. There is no reason to doubt Tönnies' sincerity and his endeavour for scholarly objectivity. But his sympathy for forms of social life of the Gemeinschaft character made him ascribe to them all kinds of virtues which exact research cannot corroborate. The picture, for example, which Tönnies gives of the old village community does not correspond with reality, as was shown some years ago by Kruijt (1955). With regard to Gesellschaft Tönnies was inclined to emphasise all its unpleasant characteristics. Many of his statements about the forms of social life with a Gesellschaft character are definitely wrong. This sturdy Frisian gave three generations with nostalgia for old fashioned rural life a scientific excuse for opposing the adjustment of rural life to the conditions of modern society. In many cases he obstructed the way for rural sociologists towards a correct understanding of the changes in rural social organisation, their background and their consequences. 
Tönnies cannot, however, be blamed for all which has been done and said in his name. The Belgian socialist Hendrik de Man (1937) coined the term "vulgar Marxism" for a crude and simplified materialism by which many so-called Marxists - and non-Marxists - thought they could explain human behaviour. By analogy of this one could also speak of a "vulgar Tönniesism". There is an uncritical glorifying of oldfashioned rural life which at least in part is based on Tönnies' ideas but which would have been quite unacceptable for his scholarly mind (Plessner, I955; Kötter, I958). This does not alter the fact, that the way in which Tönnies presented the dichotomy Gemeinschaft - Gesellschaft gave rise to misinterpretation of social phenomena in our modern world.

Tönnies concept Gesellschaft is strongly influenced by the fact that he identified this formal, contractual type of social organisation primarily with capitalistic economic organisation (Tönnies, I9I 2, pp. 48-IO0). The part of his book devoted to the theory of the Gesellschaft is in fact an analysis of capitalism as he saw it. It is correct, that Tönnies states that relationships of a Gesellschaft character can be created for all kinds of goals (Tönnies, I9I 2, p. 24I). But in his consideration of associations, for example, (Tönnies, I g r 2, p. 243) their relations to capitalism are emphasised. It is perhaps the relation Tönnies perceived to exist between formal and rational social organisation of a Gesellschaft-character and capitalism which explains his remarkable attitude towards cooperatives. Co-operatives, in contrast to associations, he considers to be true Gemeinschaften. He even expects to see a regeneration of the Gemeinschaft -type of social life by means of co-operatives (Tönnies, I9I 2, Pp. 246 and 275). In fact Tönnies' attitude to co-operatives amounts to a disavowal of his fundamental concepts. A Gesellscbaft is according to him a human association based on the common rational will to reach certain well-defined limited goals. Even if in actual associations the participants or some of the participants may become personally involved, the Gesellschaft in its pure form is only an association of interests as regulated by contract or constitution. It is hardly necessary to add that according to this definition a co-operative is a Gesellschaft, even if in a co-operative as much as in any association personal relations between the members can develop. Tönnies tries to explain the break between his theory and his personal attitude by stating that the co-operative is adapted to conditions in a society of a Gesellschaft-character (Tönnies, I9I2, p. 246) but this is hardly more than a face-saving; the co-operative is essentially a Gesellschaft.

Another suggestion which Tönnies makes and which is accepted 
by many is, that man finds mental security in the Gemeinschaft but that a society with a Gesellschaft-character deprives him of this security. According to this train of thought human beings find in'the Gemeinschaft in which they are involved with their whole personality, the sympathy and the warmth of feeling they need for their mental wellbeing. In the Gemeinschaft people can trust one another because they know one another and because they know each others' mores and norms, and thus there is no need to be on guard.

In the Gesellschaft people do not associate but interests associate. In the most favourable situation feelings of the participants towards each other are neutral. Everyone follows his own interests and only when these coincide are the participants brought together. A society dominated by the Gesellschaft-type of social organisation is hard, even inhuman, and makes people feel insecure. The contacts with other people are only formal and have no background of human sympathy. Man feels at a loss because no one is really interested in him. Tönnies himself states this very clearly: "But here everyone is only for himself, and in a state of tension against everyone else" (Tönnies, I9 12, p. 48).

This is one of the most unfortunate statements ever made in sociology, just because it seems to be true, especially in respect of rural society. We all know the coutryman who feels self-reliant and mentally secure in his village community, but is totally at a loss and insecure in the formal world of a bank, a government office and in the impersonal life of the modern city in general.

It would be totally wrong, however, to blame formal organisation for that. It seems that Tönnies and many after him never quite understood the real background and the real function of formal organisation of the Gesellschaft-type in our society. It seems that they saw and see formal organisation in the first place as an efficient way for organisers to reach their own ends, whatever these ends may be. If we consider it from the point of view of the organisers, this is often true. But when we look at the origin and the function of formal organisation from the point of view of society as a whole, we have to talse into account quite different aspects.

One of the most essential differences between formal and informal organisation, and, in fact, also between Gemeinschaft and Gesellschaft, is that the informal organisation is only suited for the small group, while the formal organisation is specially suited for large groups and social systems. The actual social entities which Tönnies designates as Gemeinscbaften and which show an organisation are small ones. He does not make it quite clear whether a nation has, in his opinion, the 
characteristics of a Gemeinschaft (Tönnies, I9I 2, pp. I7 \& 303), but there is no doubt that he considers the state to be a Gesellscbaft (Tönnies, I925).

Social life in a family can be organised on an informal basis. So long as life in a village or in a small town is not too complicated and too integrated in a larget whole, the informal element in their social life can predominate. But when individuals begin to participate in larger social units, and when small groups become integrated into large systems, formal organisation becomes unavoidable because personal relations as an organisational force have only a very limited effect. The farmer and the craftsman can organise the work on the farm and in the workshop on an informal basis but an informal organisation of the activities in a factory with rooo workers would not only be less efficient than a formal one, but it would be totally impossible. The same holds for all kinds of activities in the social, cultural and political field which take place on a large scale. How can one organise Red Cross activities or other charitable activities on a national scale without a formal, that means essentially an impersonal, organisation?

Thus, the real background to the development of formal organisation, of society with a predominant Gesellschaft-chatacter, is due not to the greed of merchants and other capitalists, but to the gradual widening of the social world of individuals and groups which is characteristic of Western society in the last few centuries, especially in the rgth and 2oth centuries. The process of formalisation of social organisation in our society was also furthered by an increase of functional differentiation which made organisation of social life on aninformal basis increasingly difficult. This increase of functional differentiation is itself related to the widening of the social world, but is also a more or less independent phenomenon. The widening of the social world and the increase of functional differentiation are related to changes in many other sectors of social life but their most essential background is the rapid increase of knowledge characteristic of Western society since the Renaissance, in particular since the 18 th century.

The increase of formal organisation is not only unavoidable as a corollary to the mentioned development but without it this development would have been unbearable for the individual. Formal organisation does not deprive the individual of his peace of mind but, on the contrary, it makes it possible for him to feel at ease in a large and complicated world. Society is not large and complicated because of formal organisation, but formal organisation is essential to master a large and complicated society and to make it fit to live in. 
In the social world in which we live to-day we are to a high degree depending on people who are strangers to us; that must be so just because this social world is large. Because this world is organised in a formal way it is possible to live with strangers and to feel secure. Because our society is formally organised to a high degree a stranger in a foreign city will give me a stamp when I pay a certain amount of the right currency. Another stranger will bring my letter to the train and still another stranger will take it to the house of my friend in another foreign city. And so, owing to the formal organisation of railways, restaurants, hotels, banks etc., one can live amongst complete strangers provided one knowns the rules of the formal organisation. Living in the wide social world of our modern society without formal organisation and depending only on the power of informal organisation would mean living in complete insecurity. There would be no possibility for co-operation except with the very few with whom one would be able to establish personal informal relations. The formal organisation does not turn a stranger into a friend or make him a co-member in a Gemeinschaft, but leads to co-operation with him if he follows the rules of the formal organisation. The awareness of the existence of this possibility for co-operation makes one feel mentally secure in our modern world.

Rural man in our society has to live and increasingly wants to live in a large ever expanding social world. If he wishes to take part economically, socially and culturally in modern Western society he has no choice; he has to fit into the formal organisation of this society. The tragedy of a diminishing but still important part of the rural population in Western Europe is that it is not yet adjusted, or at least not yet sufficiently adjusted, to the formal organisation of our society. These people still try to organise for themselves their own environment on an informal basis. But they feel unconsciously that they cannot keep out of this broader social world which invades even their small community and touches them every day. That makes them feel increasingly frustrated and insecure. They are the people who are afraid to leave their village because they do not know how to behave away from their home surtoundings. They do not know the rules of the formal organisation and thus feel insecure, but not because formal organised society as such causes insecurity. Every stranger is for them still more or less a potential enemy. They think that every merchant is cheating them and that no government official, including the agricultural advisory officer, can be trusted as in their opinion they are all out for their own interest at the expense of the peasant. 
They are the people who keep away from farmers' unions and technical organisations and often from co-operatives. In short they are our backward farmers, backward not only socially and culturally, but also economically and technically.

It is difficult to give an exact idea of their number. In the Netherlands about one third of all farmers have regular contact with the advisory service, one third have an irregular and one third have no contact. Investigations have shown that there is a high correlation between lack of contact with the advisory service and no or insufficient participation in farmers' unions, co-operatives and other associations, low productivity and backward farming in general, low participation in activities outside the village, and in general lack of understanding of the modern world (Hofstee, I957 and van den Ban, 1956 and 1958 ). It may not be far wrong to say, that in the Netherlands about one third of the farmers are well integrated in the formal organisation of modern society, one third not sufficiently and one third insufficiently.

It is the task for everyone who has to do with the education of rural people to help them to understand the meaning and the function of formal organisation in our modern world and to stimulate their integration in this organisation. It is hardly necessary to say, that this is not always done. There are still people who believe that the farmer - perhaps it would be better to say the peasant-should continue to live his quiet life on his farm and in his village community as little as possible touched by the outside urban world. He should try to maintain the old social structure and organisation of his neighbouthood and his village. In this way the traditional values of rural life and rural culture in general, as opposed to the urban culture, would be kept alive, and preserved for posterity. The number of those who take this point of view is diminishing, but it would be wrong to underestimate their influence in some countries.

This romantic thought and an education based on it are detrimental not only to the material well-being but also, and perhaps even more, to the mental well-being of the rural population. This does not mean to say that personal relations, informal social organisation and social groups of a Gemeinschaft-chatacter are not of great importance in human life. In the family, amongst friends and everywhere where personal ties between human beings develop, man experiences feelings and emotions which are indispensable for his happiness and his mental equilibrium. The argument is only that it is wrong to suppose that formal organisation and Gesellschaft would have a negative effect in this respect. On the contrary, often strong personal relations and 
friendships develop in formal organisations, which originally brought only strangers together. Research has shown us, that in the newlycolonised Zuiderzee-polders in the Netherlands many of the friendships between colonists originated from contacts they had made in formal organisations (Bosker, 1956).

It is often argued that owing to the acceptance of formal organisation as the normal basis of co-operation, many forms of co-operation which took place within groups of Gemeinschaft character have disappeared. Examples are the many forms of mutual help which formerly existed in rural communities. Other causes and not the competition between formal and informal organisation usually brought about the change from one type of organisation to the other. Technical change, multiplication of activities to be carried out, increase in membership and differentiation in its social composition, changes in the social relations between the members of the group and many other social factors are usually the cause for the change from mutual help to formal organisation.

\section{REFERENCES}

BAN, A. W. VAN DEN (1956 and I958), Enkele kenmerken en eigenschappen van vooruitstrevende boeren, (Wageningen: Afdeling Sociologie en Sociografie van de Landbouwhogeschool) Parts I and II.

Blankenburg, P. von ( 1960$)$, Utber den Begriff dex Dorfgemeinschaft und seine Anwendbarkeit auf die soziale Situation der Landgemeinde, Zeitschrift für Agrargeschichte und Agratsoziologie (Frankfurt a. M.) 8,46-55.

Bosker, L. M. (1956) De duurzame relaties van de boeren in die Wieringermeer, (Wageningen: Afdeling voor Sociologie en Sociografie van de Landbouwhogeschool), manuscript.

Doorn, J. A. A. VAN (1956), Een sociologische benadering van het organisatieverschijnsel, (Leiden: Stenfort Kroese N. V.).

Farrchim, H. P.(I944), Dictionary of Sociology, (New Yotk:The Philosophical Library), p. 2 Io.

Gurvitch, G. (I950), La vocation actuelle de la sociologie, (Paris: Presses Universitaires de France), pp. 2x2-2I6.

Hofstee, E. W. (1957), Rural Life and Rural Welfare in the Netherlands, (The Hague: Government Printing Office), pp. 299-300.

Johannessen, J. (I955), Organisation in Bensdorf, W. \& Bülow, F., Wörterbuch der Soziologie, (Stuttgart: Ferdinand Enke Verlag), pp. 558-560.

KöNIG, R. (x955), Die Begtiffe Gemeinschaft und Gesellschaft bei Ferdinand Tönnies, Kölner Zeitschrift fur Soziologie und Sozialpsychologie, (Köln), pp. 348-420.

Kö̈TER, H. (I958), Landbevölkerung im sozialen Wandel, (Düsseldorf: Eugen Dietrich Vetlag), p. 66.

KRUrJT, J.P. (1955), Gemeenschap als sociologisch begrip, een kritiek op Tönnies, 
Mededelingen det Koninklijke Nederlandse Akademie van Wetenschappen, Afd. Letterkunde, (Amsterdam).

Loomis, C. P. \& BeEgle, J. A. (I950), Rural Social Systems, (New York: Prentice Hall Inc.).

MAN, H. DE (1937), De Socialistische Idee, (Arnhem: Van Loghum Slaterus Uitgeversmaatschappij).

Plessner, H. (I955), Nachwort zu Ferdinand Tönnies, Kölner Zeitschrift für Soziologie und Sozialpsychologie, (Köln), 7, 346.

TönNIEs, F. (I9х2), Gemeinschaft und Gesellschaft, 2nd edit., (Berlin: Karl Curtius). TönnIEs, F. (r925), Soziologische Studien und Kritiken (Jena: Gustav Fischer), Erste Sammlung, p. Go.

ZNANIECKI, F. (I945), Social Organisation and Institutions in Gurvitch, G. \& Moore, W. E., Twentieth Century Sociology (New York: The Philosophical Library), p. 172. 